\title{
Reform and Exploration of the Training Mode of Postgraduate with Full-time Professional Degree
}

\author{
Tao Chen ${ }^{1, a}$, Fang-an Deng ${ }^{1, b}$ and Shengzhang Ren $^{1, c}$ \\ ${ }^{1}$ School of Mathematics and Computer Science, Shaanxi Sci-Tech University, Hanzhong, China \\ act79hz@126.com, bdengfangans@126.com, 'renshengzhang1980@163.com
}

Keywords: Full-time professional degree; Postgraduate Education; talents training mode; reform; Courses System; Innovation

\begin{abstract}
Postgraduate with full-time professional degree is an important component of China's postgraduate education. Whereas, its training mode is still in the stage of exploration and construction and the process of deepening postgraduate education still faces numerous problems. This thesis takes the existing major problems as the prospective and deepens into the research on the training mode of postgraduates with full-time professional degree from connotation understanding, training objective, discipline system, practical platform, tutors team and process management on the basis of the analysis of the existing problems in the training of postgraduates with full-time professional degrees so as to promote the reform of postgraduate education and social development.
\end{abstract}

\section{Introduction}

China's education on postgraduate with full-time professional degree is an important way to culture high-end and applicable talents. In recent years, the enrollment rate of mater students with full-time professional degrees along with increasing professional types, so are their social influence. Whereas, professional master education is still in the early stage which is still not mature and lacks a set of effective training mode. This thesis will discuss about the problems existing in the postgraduate education with full-time professional degree and deepen the analysis and research on the postgraduate training with professional degree and propose the methods and mindsets of reform.

\section{Problems existing in the Training of Postgraduate with Full-time Professional Degree}

\subsection{The Training Modes of Academic and Applied Postgraduates are almost the same}

Recently, the training modes of academic and professional applied postgraduates in many universities are almost the same. Both regard exam credits as the major standards of examination. In the selection of professional degree talents, practical review and examination credits are not on the equal footing, instead, when students enter school, they are still mainly imparted with systematic and theoretical courses, and the courses system and contents are not greatly improved, professional degree courses practices lack teaching features; fail to take the application of basic theories and learning methods as the core contents.

2.2 Full-time Professional Master Training has not formed a scientific and established system

Courses resources are insufficient and student's knowledge system is not reasonable, which mainly includes: insufficient levels on the setting of postgraduate courses; poor orientation of the setting of courses for academic masters and professional masters; rare space for courses selection. In order to gain enough credits, students should learn those courses which are even not related to the courses they select. This leads to extensive but not intensive knowledge structure of the students, they know a lot but not professional which is not beneficial for students to accumulate enough knowledge on a major. Besides, it deteriorates students' activity in class and leads to reluctant learning in class as a result [1].

\subsection{Teachers Team and Assessment System are to be Optimized}

The existing teachers participating in the teaching of postgraduate with full-time professional degree are predominated by academic teachers with strong theories. Teachers with rich practical experiences and the professional qualifications are not sufficient yet. Assessment on teachers , 
especially tutors of postgraduates with professional degree are still focused on thesis, topics and students' credits and other standards for academic postgraduates which can rarely display the features of profession and applicability[2].

\subsection{The Effective Means of the Combination of Industry and Education and Quality Control System are not sound}

During the training of postgraduate, there are evident tendency towards more theories than practice and more science than technology. Thesis filing and influential factor also become the standards to evaluate students in the training of postgraduate students with professional degree. "a teacher in enterprise will lead you around an enterprise," has become the highlights of the training of postgraduates with professional degree. Combination of industry and education has been "formalized" to a certain degree. This becomes a difficulty facing the units training postgraduates. How to effectively realize the combination between industry and education in the training cycle of postgraduate with professional degree requires additional design of traditional thesis-based training framework.

\subsection{Lack of Training Means and Innovation}

In the existing training mode of postgraduates with professional degree, theoretical lessons imparting evident knowledge are still in the predominating position. Even training units and teachers themselves have not fully recognized the importance of invisible knowledge, let alone imparting invisible knowledge as a part of teaching content. Theoretical teaching lessons or textbooks should not be the sole source of invisible knowledge. Experience in practice will be much more conducive to training ability. We can see that the existing teaching methods of professional degree are somewhat stereotyped; teaching contents are derailed from times which can not reflect the latest technological achievements; teaching means innovation are also not evident accompanied by poor enthusiasm of students.

\subsection{Poor Use of the Incubation Base for Postgraduate Education}

Although environment's importance has been realized in the existing training mode of postgraduates with professional degree, it is only limited to guarantee the duly accomplishment of the learning hours of theoretical courses in the university, and a closer relation between the topic of a thesis and production technology. Universities and enterprises mainly focus on low-level cooperation that although a joint training mode is established, it's predominated by universities while enterprises are just affiliates and could not play their roles effectively and enthusiasm. Universities own huge HR resources advantage while enterprises also have high-end lab resources and the needs for technological innovation while the two aspects are not well combined, therefore, the use of incubation base for postgraduates is evidently poor and have not fully played its role in enhancing the practical ability and innovative capability of postgraduates with professional deg

\section{Mindsets and Means to Reform the Training Mode of Full-time Postgraduate with Professional Degree}

\subsection{Deepen into Understanding the Connotation of Professional Degree}

Professional degree is mainly to train professional ability and ethnics required for postgraduates in specific professions, who are qualified to apply some theories, knowledge and technologies to effectively participate in professions. It focuses on curtaining talents to be adapted to the features truly needed in real specific industries or occupations. Combining with the connotation of the training of professional degree, the advantages of local universities should be fully played; promote local industry association, industrial authority and head enterprises to participate in the training of postgraduates with professional degree in an all round manner; advocate the connection between the professional degree education and industry professional qualification examination and the connection between students and enterprise so as to enhance the social recognition on the postgraduates so as to guarantee the training quality of postgraduates with professional degree[3]. 


\subsection{Clarify the Training Objects of Professional Degree}

Postgraduate education with professional degree aims to culture high-end applied and complex talents with special occupations and connect that with designated job qualification. Given training objects, we should meet industrial and social demands while the core is to train occupational ability and pay attention to the tight combination between knowledge and occupation. Professional settings should be of clear industry background and occupational feature which outstands this occupation's demands for creative talents. It should be designed combining with the industry development rules and changing industrial structure.

\subsection{Establish a Talents Training Courses System Centered by Industrial Knowledge}

The original intention of the training of postgraduates with professional degree is to enhance the professional ability of industrial technicians. How to penetrate the ideal of industrial technologies into the whole process of the training of postgraduates with professional degree, which mainly includes courses system setting, teaching method and practical mode, etc..

The setting of courses system pays more attention to the explanation of practical industrial problems. It's necessary to set courses system being closely related to the development of industrial technologies. Enlargement of the proportion of selective courses and the strengthening of industrial technical professional courses can be adopted to provide more opportunities for students to restore industrial technical knowledge[4].

Teaching means focus on combining with industrial practice. On one hand, it can promote more enterprise technicians to participate in the whole process of education and teaching and enhance the tentativeness of teaching connotation; second, it can transfer some teaching sites of some professions to enterprises and deepen students' recognition to professional knowledge in the form of on-site teaching; third, change the traditional textbook-based teaching, promote case-based teaching and use practical cases to activate students' learning interests, deepen students' understanding on the concrete practical problems and the treatment, train students' ability to research practical problems and promote the ability of postgraduates with professional degree to integrate and covert the theories and practice.

\subsection{Establish a Sound Platform for the Education and Practice of Postgraduates}

The platform for the education and practice of postgraduates is a solid guarantee for the training of postgraduates' practical ability and occupational ability. To establish a sound platform for the education and practice of postgraduates, the following aspects can be adopted concretely: first, deliver projects to support the postgraduates education project and scientific practice and the construction of practical training platform in the form of topics and projects and based on different schools, key labs and institutes; realize the integration of scientific teaching agency and practical platform and provide quality software and hardware services for postgraduate courses teaching and innovation and entrepreneurship; second, combine with superior departments to support universities to join hands with enterprises and scientific research institutes to establish special fund program of the incubation base on postgraduate education; actively extend outside and fully absorb social resources like alumna; focus on establishing postgraduate education incubation base in enterprise and institutions, government practical departments and famous enterprises dominated by alumna and let enterprises and scientific research institute participate in training postgraduates in the whole process, clarify liabilities and commitments and establish the managerial act and operation fee guarantee measures in the practical link; try the order-based and pre-employment training modes so as to provide talents support for partner units and mobilize the enthusiasm of partner units [2,5-6].

\subsection{Improve the Building of Tutors' Team}

Tutors' guidance at school and practice in practice base are equally important in the training of postgraduates with professional degree. Therefore, compared with academic postgraduates, to fully enhance the postgraduates' ability on scientific research and practice, "tutors group" should be arranged which from both school and outside, the best combination of which should be school tutor (group) with deep theoretical basis and rich experiences in guiding postgraduates and a tutor outside school who has rich practical experiences. Furthermore, in the selection of tutors outside school, stick 
to the principle of "ensure quality and maintain flexible" and realize "appoint people by abilities", establish a tutors mobile management mode and adopt a scientific, just and overall tutors examination system in the principle of "survival of the fittest" [7-8].

\subsection{Establish Thesis Standards and Approval Methods for Postgraduates Education of Full-time Professional Degree}

The postgraduate education of full-time professional degree is mainly to train high-end applicable talents, the thesis of which focuses on checking the postgraduates' abilities to innovate, manipulate, develop technologies, and extend market and their comprehensive quality. The thesis must outstand social, economic and applicable values while footing on practice. It strengthens application orientation, which can be accomplished in forms like research report, investigation report, planning and design, product development, cases analysis, program management, graduate design and literary and artistic work. The topic of thesis should come from real problems in social practice or work practice which should be with clear practical meaning and applicable values; thesis defense are in various forms while defense members should include experts with professional technical occupations in the relevant industrial practice industry.

\subsection{Improve Quality Control during Training}

To enhance surveillance to the key links during training in an all round manner is an efficient means to enhance the training quality of postgraduates. In teaching link, manage the setting of courses and imparting process systematically and in a standard manner; in practical link, improve supported facilities in postgraduate practice base, select the second tutor with rich experiences, improve practical teaching and assessment system and strengthen the training of practical innovation and engineering application ability of postgraduates; professional thesis should surround the problems that should be urgently solved in practice or restrict the development of enterprises, which should indicate the combination of academics, applicability and engineering quality; elimination mechanism should be introduced during training to enhance the positivity and initiative of postgraduates and further enhance the training quality of postgraduates with professional degree[4,9].

\section{Conclusion}

Full-time postgraduates education with professional degree is a key measure of talents training reform since 2009, which is beneficial to realize the enhancement of technical innovation, lay a solid foundation for mass innovation and crowd entrepreneurship, the enhancement of vitality and attractiveness of vocational education and lay foundation for the integration of academic education and vocational qualification. Outstanding vocational qualification knowledge and ability restoration will be key steps of postgraduate education reform with full-time professional degree in the future, which requires improved talents training system and further exploration of the means to effectively enhance the postgraduate training level of professional degree.

\section{Acknowledgment}

This paper is supported by Graduate Education Reform Project by Shaanxi Sci-Tech University (NO: SLGYJG1505).

\section{References}

[1]. LIN Chao, ZHU Caichao, SUN Yuefang, CAI Zhiqin. On Full-time Professional Degree Postgraduate Training Innovation Mode[J].The Guide of Science \& Education, 2015,12:59-64 (In Chinese)

[2]. ZHANG Yu-hui .A Study on Comprehensive Educational Reforms of Graduates in Full-time Professional Degree[J].Journal of Fujian Jiangxia University,2015,5:76-87 (In Chinese) 
[3]. CHEN Suhua, WANG Weimin, JI Hongwu, et al. Research and Practice on Optimizing Teaching Methods of New Food Processing Technology Courses[J]. Farm Products Processing, 2016, 4:77-79 (In Chinese)

[4]. ZHANG D, CHEN X. Survey on the Training for Full-time Professional Degree Postgraduate of Research Universities [J].Journal of Higher Education,2011,2: 018 (In Chinese)

[5]. Youquan G, Weina P, Zhiyue P, et al. Investigationon Full-time Professional Graduate Student Training Mode Operation-Based on the surveying data in 14 key universities in China [J]. Modern Education Management, 2012, 1: 024.

[6]. Flynn T W, Wainner R S, Fritz J M. Spinal manipulation in physical therapist professional degree education: A model for teaching and integration into clinical practice[J]. Journal of Orthopaedic \& Sports Physical Therapy, 2006, 36(8): 577-587.

[7]. Dun-rong B I E, Xue-wen T A O. Reflection and innovation on quality assurance system of graduate education for professional degrees in China[J]. Journal of Higher Education, 2009, 3: 011.

[8]. Wallin D L, Smith C L. Professional development needs of full-time faculty in technical colleges[J]. Community College Journal of Research and Practice, 2005, 29(2): 87-108.

[9]. ZHANG X, SONG M. Process Management and Quality Control for Professional Degree Theses Prepared by Full-Time Master's Students [J]. Journal of Graduate Education, 2011, 3: 014. 